\title{
Long chain 1,14-diols as potential indicators for upper water stratification in the open South \\ China Sea
}

XiaOWeI ZHU ${ }^{13}$, GUODONG JiA ${ }^{2}$, WeIHAI XU ${ }^{13}$, WeN $\mathrm{YAN}^{134}$

1 Key Laboratory of Ocean and Marginal Sea Geology, South China Sea Institute of Oceanology, Chinese Academy of Sciences, Guangzhou 510301, China

2 State Key Laboratory of Marine Geology, Tongji University, Shanghai 200092, China

3 Innovation Academy of South China Sea Ecology and Environmental Engineering, Chinese Academy of Sciences, Guangzhou 510301, China

4 University of Chinese Academy of Sciences, Beijing 100049, China

Long chain 1,14-diols have been widely studied in typical upwelling areas, but less investigated in open seas. In this study the 1,14-diols in a sediment core, covering a history between $42 \mathrm{ka}$ and $12 \mathrm{ka}$, were studied to investigate their potential to indicate upper water stratification in the open northern South China Sea (SCS). Downcore records of 1,14diol fractional abundances, diol index 1 (DI-1) and diol index 2 (DI-2) changed in parallel, with a prominent increase at $\sim 14.5 \mathrm{ka}$, likely corresponding with the Bølling warming event. This pattern is different from what has been observed in typical upwelling regimes, showing an insignificant relationship between DI-1 and DI-2. Moreover, these records showed a generally inverse variation pattern with records of primary productivity, further suggesting that they are not likely applicable as upwelling indicators in the study area. However, the 1,14-diol records changed positively with sea surface temperature (SST), as well as the difference between SST and subsurface-temperature, hence suggesting their potential to indicate upper water column stratification in the open SCS. This occurrence might be associated with the productivity of 1,14-diol precursor (i.e., Proboscia diatom), which is sensitive to the variation of mixed layer depth in oligotrophic open oceans and lacks of competitiveness relative to the more heavily silicified diatoms under normal $\mathrm{Si}$ replete upwelling conditions. Our result also suggested that the East Asian monsoon may have played an important role to modulate riverine terrigenous organic matter input to the study area. 